\title{
Evaluation of Milk Production at Tigaie Sheep Reared in Romania
}

\author{
Constantin PASCAL ${ }^{1,2^{*}}$, Ionică NECHIFOR ${ }^{1,2}$, Marian Al. FLOREA ${ }^{1,2}$, Stelian Vasile DARABAN ${ }^{3}$ \\ ${ }^{1}$ University of Agricultural Sciences and Veterinary Medicine - Faculty of Animal Science, Iași, Romania \\ ${ }^{2}$ Agricultural Station of Research and Development for Sheep and Goat Growing Popăuţi - Botoșani \\ ${ }^{3}$ University of Agricultural Sciences and Veterinary Medicine - Faculty of Animal Science, Cluj-Napoca \\ *corresponding author: pascalc61@yahoo.com; pascalc@uaiasi.ro
}

Bulletin UASVM Animal Science and Biotechnologies 76(1)/ 2019

Print ISSN 1843-5262; Electronic ISSN 1843-536X

DOI:10.15835/buasvmcn-asb: 2018.0005

\begin{abstract}
Biological material subjected to research was represented by females belonging to Țigaie breed which are in different lactations. Research has been expanded to six consecutive lactations, period in which the followed objectives were represented by: quantity of milk sucked by lambs during lactation, the quantity of milk produced in each lactation period when the flock is located in the milking situation exclusively and the total quantity of milk obtained in each controlled lactation. The work methods used are accepted by experimental practice. During the period of lactation was used the control coefficient method; exclusively for milking period was applied the AT4 method respecting the technical specifications specified by the International Committee for Animal Recording. Also, to eliminate the influence of environment, age, nourishment and maintenance conditions, in each season the period was the same (May-September) and had the same conditions of nourishment, maintenance, sheltering etc. Statistical processing of obtained data at the end of evaluation of milk quantity consumed by lambs show that in first 28 days of suckling, Tigaie breed sheep furnish around $42 \%$ from the total milk quantity consumed by lambs during suckling period. Based on this observation we could say that application of selection at sheep on the basis of lambs' corporal weight at age of 28 days is more indicated and efficient. In case of appreciation of milk quantity gathered by milking could be observed the fact that face to maximum level reached in first lactation the total estimated quantity was higher with $29.29 \%$ in second lactation and after that gradually decrease and record negative values in the last controlled lactation. Effectuation of a rate between milk quantity consumed by lambs and milk quantity obtained after their weaning show the existence of a close rate, with the exception of first lactation when sucked milk quantity was higher with $15.8 \%$ face to level of milk production gathered by milking. Statistical processing of information highlighting that between the amounts of milk consumed by lambs in the suckling period, there have been significant differences for $\mathrm{P}<0.01$ and for $\mathrm{P}>0.05$. During the six controlled lactations the maximum milk production was recorded in the second lactation and was of $139.67 \mathrm{~kg}$ of milk, superior with $29.29 \%$ than level obtained in the first lactation and with 5.29\% lower to the total estimated production for the third lactation.
\end{abstract}

Keywords: sheep milk, Ţigaie sheep, Romanian sheep, sucked milk, milked milk.

\section{Introduction}

In Romania exploitation of sheep for milk production has a special importance for private breeders because, unlike other productions (meat, wool), involving the development of income in a shorter period of time, the production and recovery of milk leads to achieve constant incomes over a time period of 6-8 months. Therefore, farmers in Romania receive technical and financial support from state on condition that livestock to be included in programmes of improvement, to be subject to control of performance production and to apply directed reproduction. The purpose of such measures is to re-launch the sector of sheep breeding, especially in traditional mountain basins, and Romania to become an important producer of sheep's milk and products derived from the processing of such production. Currently, milk 
production is used in various forms of traditional or industrial processing. Taking into account these trends in Romania, in 2015, the total production level of sheep's milk has exceeded the increase of $15,000 \mathrm{t}$ in growth with $10 \%$ compared to the milk production recorded in 2012 (Pascal, 2015; Darban, 2006). In this context the current research aimed to define the potential for milk production for one of the most widespread breed in Romania, respectively Țigaie, which together with Țurcană have over 75\% from national breed structure.

\section{Materials and methods}

Biological material was represented by a total number of 100 females belonging to Tigaie breed which were housed in the farm of a research station for small ruminants. To fulfil the main aim, represented by evaluation of lactogen capacity, the batch was subjected to the same experimental treatment for six consecutive lactations. The working methods used in applicative research are accepted in experimental technique. So, for breastfeeding period the milk quantity consumed by lambs was determined through the method elaborated by Th. Nica, included as official method in Technical instructions on the estimation and certification of the quality of the reproduction material in animals, Ministry of Agriculture and Food, from Romania, detailed by Ghiță et al., 2006. In according with this method, evaluation of milk quantity consumed by lambs is determined based on total gain achieved by the lambs which are in breastfeeding period. For an objective evaluation of milk quantity consumed by lambs, in each season breastfeeding took place for 75 days and were weighted a number of 100 lambs. Because during research were outflows from flock, control of milked milk was made on a batch of 50 females being applied the AT4 standard method respecting the technical demands required by International Committee for Animal Recording. In according with this method, determination of milk quantity gathered in exclusive milking period is determined into a standard interval of lactation. Also, in according with this method, appreciation of milked milk quantity in the control day is based on effectuation of some productive controls applied alternatively and at only one of the daily milking.

Having in view the fact that research was carried out on a long period of time we aimed that experimental treatment to be identical, for each lactation. So, at each controlled lactation flocks were kept during day on graze and in the evening in shelters having the same accommodation and nourishment conditions. Effectuation of productive controls were realised at regular intervals of 28 days and was extended from May to September.

Under the applied system, the total duration of lactation was 225 days. For the period of lactation the first control was planned at 28 days from the moment of parturition and the second the 58 day of lactation and weaning took place at the age of 75 days. In each milking period, between lamb weaning and the mother female, controls were placed at regular intervals of 28 days.

Individual milk yields have been recorded alternated, at a control at the morning milking and in the evening milking at the next control to, and so on.

Estimating the average total production of milk was carried out using the Fleischmann method.

Milk yield $[\mathrm{kg}]=\mathrm{L}_{1} \cdot$ int $_{1}+\sum_{i=2 a n}\left(\frac{\left(\mathrm{L}_{i}+\mathrm{L}_{i-1}\right.}{2} \cdot\right.$ int $\left._{i}\right)+\mathrm{L}_{n} \cdot 14$

where:

$\mathrm{L} 1=$ milk yield at $1^{\text {st }}$ monthly test;

$\mathrm{Li}=$ milk yield at $\mathrm{i}^{\text {th }}$ monthly test $(\mathrm{i}=1, \ldots, \mathrm{n})$;

$\mathrm{Ln}=$ milk yield at last test;

int 1 = number of days from kidding to $1^{\text {st }}$ monthly test;

inti $=$ number of days between monthly tests (i-1) and $\mathrm{i}(\mathrm{i}=1, \ldots, \mathrm{n})$;

$\mathrm{n}=$ total number of monthly test for a specific animal.

The achieved result have been input into the data base, used to run statistical analysis with the algorithm REML (REstricted Maximum Likelihood), which provide the achievements of the statistical parametric estimators within the normal range. The REML estimator is the maximum likelihood estimate of the parameters which uses only the information not contained in the estimate of the regression vector, and thereby automatically corrects for the degrees of freedom which are lost in estimating the regression vector. 


\section{Results and discussions}

Sheep selection based on the assessment of milk production by applying, for each lactation, productive controls represents a difficult task to implement because in each country is observed a great diversity in terms of the following aspects:

- feeding sheep in different annual periods is uneven;

- conditions for accommodation and maintenance of the existing farms are highly varied;

- during control periods flocks are found dispersed in vast areas involving higher costs for the application of productive controls;

- grazing areas are found sometimes in less accessible areas.

Therefore, in Romania, after 2007, the concerns have been intensified in order to establish a framework under which the control of milk production in sheep can have place, and thus to create a technical framework to support an increase in individual milk production in sheep.

Evaluation of milk quantity of milk in lactation period. Lactation period extends between two moments, namely between that of parturition and the weaning of lambs. After colostrums phase, during the first $15-25$ days, breast milk is the source of exclusive feeding of lambs. Studies carried out in this respect show that in the first 20 -
25 days lambs consume between 600-800 g/day and between 1000 and $1200 \mathrm{~g} /$ day until the age of 30-45 days (Pascal et al., 2009; Pascal, 2015; Taftă, 1996; Mochnacs, 1978). It follows that, in these intervals, the amount of milk needed for a $\mathrm{kg}$ of body weight is between $4.0-5.5 \mathrm{~kg}$, being influenced by the age and quality of breast milk.

Table 1 presents the results of a synthesis of data obtained from the processing of data relating to the estimation of the amount of milk consumed by the lambs on the two ranges of the lactation period. From analysis it is found that the average amount of milk consumed during lactation, although it lies relatively close between the limits, in each lactation, there are some differences between the mean values of the quantity of milk consumed by lambs within those 75 days. Many of these differences have a high degree of significance for the statistical thresholds taken into account (table 1).

The largest amount of milk consumed by the lambs on the interval of those 75 days of lactation was $63.26 \pm 0.70 \mathrm{~kg}$ and was registered in the control applied in 2013, when the flock of mother sheep was in the third lactation. This level of milk consumption was higher with $6.07 \mathrm{~kg}$ compared to the amount consumed during lactation in 2011,

Table 1. Milk production for the lactation period $(\mathrm{kg})$

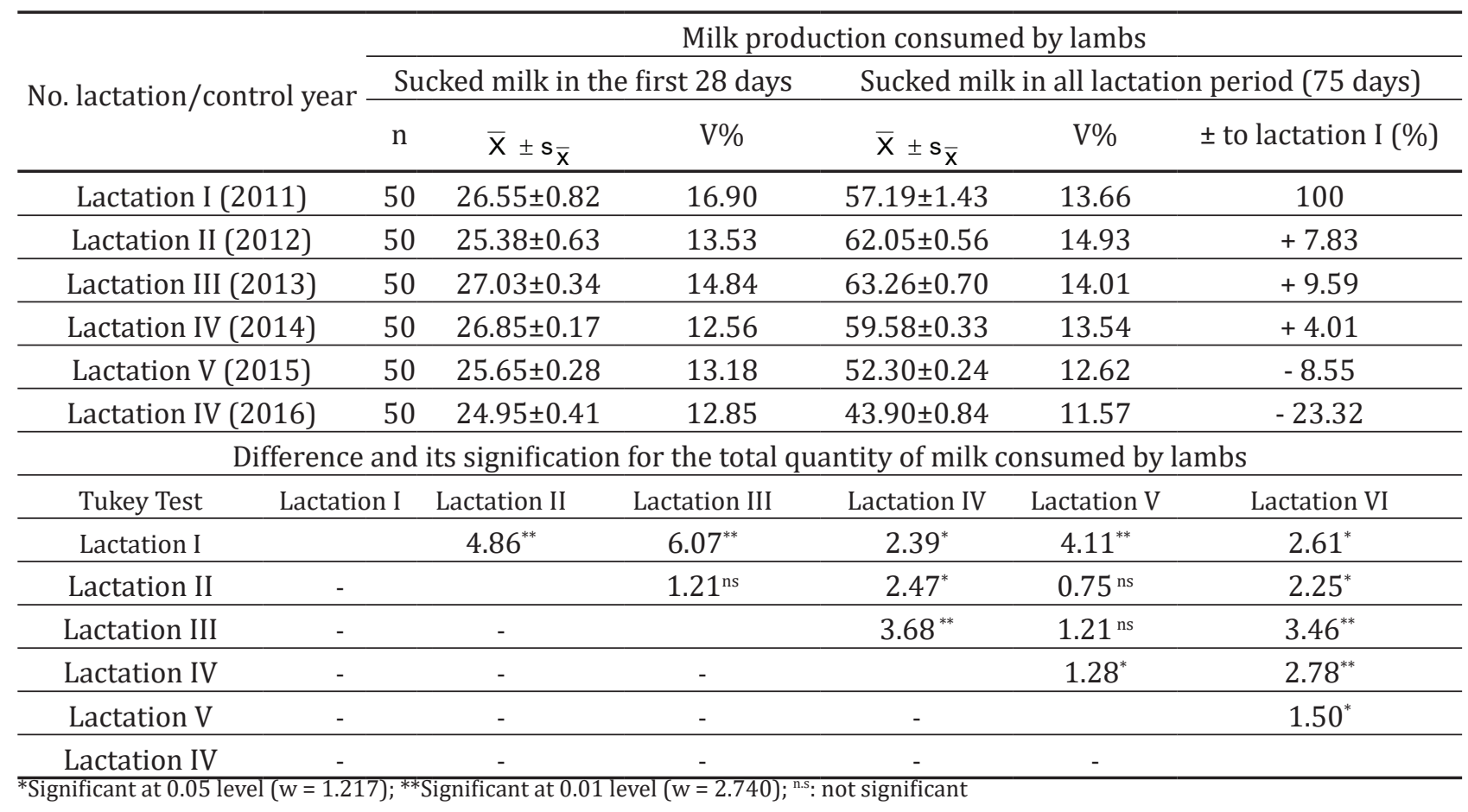




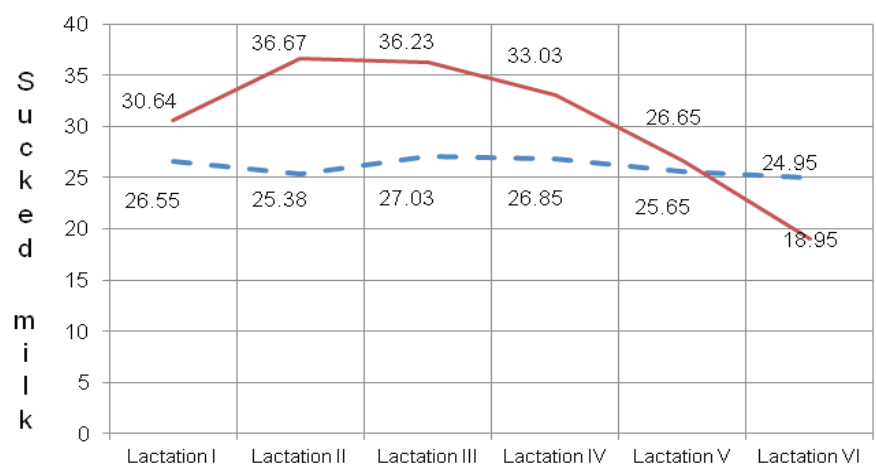

Figure 1. Dynamics of milk quantity consumed in the first 28 days in comparison with the total quantity consumed in those 75 days of breastfeeding $(\mathrm{kg})$

Table 2. Genetic estimators specific to the lambs of Tigaie breed which are in the lactation period

\begin{tabular}{|c|c|c|c|c|c|}
\hline \multirow{2}{*}{ Age of lambs (days) } & \multicolumn{2}{|c|}{ Heritability $\left(\mathrm{h}^{2}\right)$} & \multicolumn{2}{|c|}{ Repeatability (r) } & \multirow{2}{*}{ Correlation (p) } \\
\hline & $\mathrm{T}$ & $E_{m}$ & $\mathrm{~T}$ & $E_{m}$ & \\
\hline 15 & 0.22 & 0.28 & 0.31 & 0.27 & 0.79 \\
\hline 28 & 0.26 & 0.28 & 0.30 & 0.26 & 0.73 \\
\hline 45 & 0.24 & 0.34 & 0.34 & 0.30 & 0.54 \\
\hline 55 & 0.23 & 0.31 & 0.32 & 0.28 & 0.41 \\
\hline 75 & 0.18 & 0.23 & 0.20 & 0.16 & 0.23 \\
\hline
\end{tabular}

during which mothers at the first lactation were subject to productive control.

As regards to the intensity of lactogen secretion the data processing show that during the first 28 days of lactation the sheep of Tigaie breed provide about $42 \%$ of the total quantity of milk consumed by the lambs in the 75 days of lactation (fig. 1).

Based on the data presented in Table 1 and Figure 1 we can specify that Tigaie sheep breed have in the first part of lactation a superior lactogen potential by ensuring to its own products nutrient resources supporting better.

The curve described by the level determined for the average quantity of milk sucked in the first 28 days postpartum has on all six controled lactations a linear expression and the one determined for the next 47 days of lactation has a total width of upward in the first three lactations then enters a phase of regression, sharper in the last two controlled lactations. Based on this observation is distinguished the fact that the application of selection in sheep based on body weight of lambs at the age of 28 days is more eloquent and more effective.
The new data obtained converge with other obtained by of research teams that which analyzed and other breeds of sheep. Recent studies conducted by Cardellino R.A., and Benson M.E., 2002, cited by Pascal et al., 2010, show that the biggest differences recorded between lactation capacity and intensity of breeding lambs were found at the beginning of lactation. The same team of authors state the fact that between the age of the sheep and the lactation capacity there is a positive correlation.

The inclusion criteria for the selection of the weight of lambs carried out within the first 28 days of life is justified by the fact that during this period the breast milk represents the only source of food. From the data presented in table 2, it is found that the intensity of the link between the amount of milk sucking and intensity of breeding lambs is amended in relation to the period of determination. And from that perspective, but also under other outputs are found again that the most accurate information is provided on the intensity of breading lambs carried out during the first four weeks of life. For these reasons it is advisable that in the improving works which have as a criteria 
Table 3. Milk production for the milking period (kg)

\begin{tabular}{cccccccc}
\hline \multirow{2}{*}{ Control season } & $\mathrm{n}$ & \multicolumn{4}{c}{ Estimation of the total production of milk realized in each lactation } \\
\cline { 3 - 8 } & & $\overline{2}$ Sucked milk & \multicolumn{2}{c}{ Milked milk } & \multicolumn{2}{c}{ Total milk yield } \\
\cline { 3 - 8 } & & $\overline{\mathrm{x}} \pm \mathrm{s}_{\overline{\mathrm{x}}}$ & $\mathrm{V} \%$ & $\overline{\mathrm{X}} \pm \mathrm{s}_{\overline{\mathrm{x}}}$ & $\mathrm{V} \%$ & $\overline{\mathrm{X}} \pm \mathrm{s}_{\overline{\mathrm{x}}}$ & \pm to lactation I (\%) \\
\hline Lactation I & 100 & $57.19 \pm 1.43$ & 13.66 & $41.57 \pm 3.09$ & 13.28 & $98.76 \pm 0.84$ & 100.00 \\
\hline Lactation II & 100 & $62.05 \pm 0.56$ & 14.93 & $77.62 \pm 3.75$ & 15.41 & $139.67 \pm 0.38$ & +29.29 \\
\hline Lactation III & 100 & $63.26 \pm 0.70$ & 14.01 & $69.44 \pm 3.97$ & 20.41 & $132.27 \pm 1.55$ & +25.33 \\
\hline Lactation IV & 100 & $59.58 \pm 0.33$ & 13.54 & $60.52 \pm 4.17$ & 18.48 & $120.10 \pm 2.18$ & +17.76 \\
\hline Lactation V & 100 & $52.30 \pm 0.24$ & 12.62 & $53.16 \pm 2.13$ & 15.60 & $105.46 \pm 3.01$ & +6.35 \\
\hline Lactation IV & 100 & $43.90 \pm 0.84$ & 11.57 & $48.05 \pm 3.97$ & 14.32 & $91.85 \pm 2.88$ & -6.99 \\
\hline
\end{tabular}

the selection of lambs based on lactation, lambs weighing should be done within the first 28 days of the onset of lactation, meaning when the correlation between these two characters has a value greater than 0.75 . In the second part of the lactation the intensity of the link and correlations is reduced significantly $\left(r_{p}: 0.41 ; r_{p}: 0.23\right)$

Analysis of heritability coefficient specific to various ages from the neonatal period indicate reduced values for live weight at weaning and for breeding intensity of suckling lambs. Also, the mean values of heritability determined by regression method of a descendant parent are higher by about $42 \%$ of those calculated by intractable correlation. The heritability determined for the live weight of lambs determined at different ages during the period of breastfeeding is almost similar with other values for other breeds of sheep (Pascal et al., 1997; Fogarty et al., 2003; Safari et al., 2005; Pascal et al., 2014).

Determination of repeatability is extremely important in animals' selection because during exploitation some characters will develop and will have a repeated manifestation during time and into a quite changed environment. It is the case of milk production from sheep which under the influence of different factors have a different level for each lactation periods and in this case repeatability coefficient represent a rate between variance of real production capacity and variance of individual performance. In case of repeatability determination for milk quantity consumed by lambs during breastfeeding period could be observed that the values are higher face to heritability ones because in determination of this estimator are took in account also the influences due to permanent environment and were utilised data from more breastfeeding cycles. The highest value was determined for milk quantity consumed by lambs after 45 days from lactation starting.

Knowing the both genetic estimators represent an essential demand for determination of breeding value because based on them is determined the regression coefficient between phenotype and genotype with which we can correct the selection difference of each sheep face to population mean.

The high value of the coefficient of variability was determined by estimating the quantity of lactation milk on the basis of the intensity of breeding lambs suggests heterogeneity for the breastfeeding ability of adult ewes and involves an intensification of the work of selection.

Evaluation of the quantity of milk exclusively from the milking period or milk quantity, the material is very important because the total quantity of milk milking and exploited depends largely on the effectiveness of the breeding of sheep. Under these circumstances the selection of sheep on the basis of the results obtained after the productive checks, increases in importance and guarantees also the increase of the genetic gain in subsequent generations.

If the kernel of 100 sheep subjected to production control during six successive lactations there were some differences in the maximum level of total production achieved. Highest level of total production of milk produced on a specific range of normal lactations was recorded in the period in which the same batch was in the second lactation. In relation to the maximum level attained during the first lactation the estimated total quantity was higher with $29.29 \%$ in the second lactation, after which it gradually reduces and registers negative values in the last controlled lactation. 


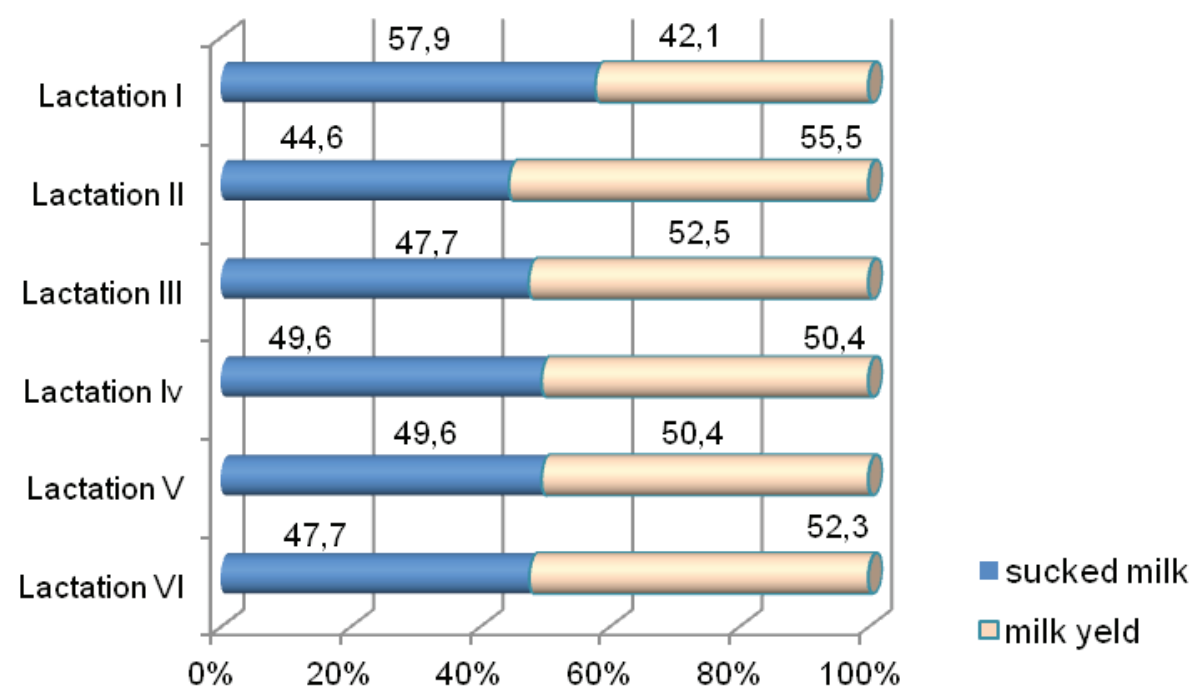

Figure 2. Ratio of milk quantity milked and sucked in the average total production per lactation (\%)

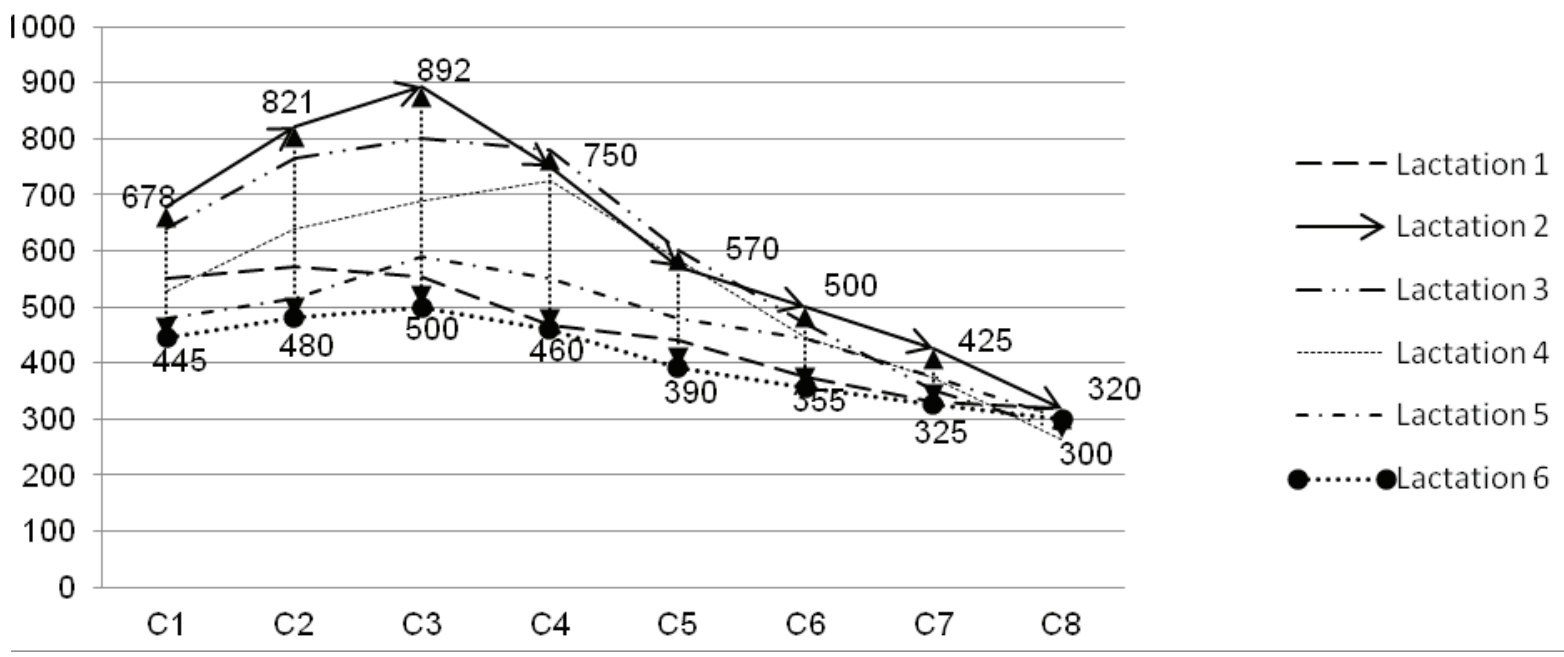

Figure 3. Dynamics of lactation curve during productive live (g/day of control)

(Notes: C1.....C8 - no. of controlled; intervals=28 days)

Determination of ratio between the amount of milk consumed by lambs and that obtained when applying milking after weaning lambs shows relatively similar and equal proportions in the total production of milk produced in each controlled lactation. An exception to this finding is observed in the case of determinations on the first lactation (fig. 2). In this case, the quantity of milk consumed by lambs during the breastfeeding interval was higher by $15.8 \%$ compared to the average level of milk production obtained by milking practiced after weaning the lambs. Also, from the obtained data could be observed the higher rate of milk quantity consumed by lambs was higher when females' batch was at first lactation. This situation was due mainly to the fact that total milk production from a certain lactation, at which the ratio was made had an inferior value in comparison with the lactations which followed.

In Figure 3 is illustrated the diagram of the lactation curve for Tigaie breed on each of the six successive lactations subject to milk production control. In relation to the estimated average values on each lactation and control period it is found that the maximum threshold has been reached in the second lactation and during the same the biggest productions are obtained between the second and the third control interval.

After the maximum peak reached at the second or the third control interval, the curve shows a progressive decrease until the end of lactation, which can be observed in figure 3 . At the 
same graphical expression of the lactation curve arrives also Alderman et al., 1995; Komprej et al., 2003; Carta et al. 1995; Ptak et al., 1993; PeraltaLailson et al., 2005; during some similar research carried out on other sheep breeds in Europe.

Also, Oravcová M. et al., 2006, obtained data relatively similar by applying the model to test to the breed's Țigaie and Valahă (Ţurcană) bred in farms from Czech Republic and determines maximum production threshold from each lactation in the range 20-50 days after lambing, and production with the highest level was registered by sheep in the third lactation.

Acknowledgements: The research has been financed by the Ministry of Agriculture and Rural Development through the research programme ADER 2020, project code PS 5.1.9.

\section{Conclusions}

Analysis of lactogen secretion show the fact that in the first 28 days of suckling Tigaie breed sheep provides around $42 \%$ from the total quantity consumed by lambs in those 75 days of suckling, so are provided information on lactogen potential still from the first period of suckling.

Graphical expression of curve realised on the basis of estimation of total mean quantity of milk consumed by lambs in the first 28 days of life had in all controlled lactations a linear evolution, and for the determined for interval 28-75 days had an ascendant evolution in the first three lactations and after that had a decrease, more accelerate, in the case of the last two controlled lactations.

Based on data we can say that sheep selection function of suckling capacity, estimated by the rhythm of accumulation of live mass of the own products in the first 28 days from beginning of suckling, is more efficient because correlation between those two characters have a value higher than 0.75 .

In relation with estimated mean values for each lactation and control interval could be observed that at Tigaie breed maximum level was reached in second lactation and on duration of the same lactation the highest productions are obtained between second and third control interval.

\section{References}

1. Alderman G, Cottrill BR (1995). Energy and protein requirements of ruminants. $\mathrm{CAB}$ International, Wallingford, UK, $159 \mathrm{pp}$.

2. Cardellino RA, Benson ME (2002). Lactation curves of commercial ewes rearing lambs. J Ani Sci, 80: 23-27.

3. Carta A, Sanna SR, Casu S (1995). Estimating lactation curves and seasonal effects for milk, fat and protein in Sarda dairy sheep with a test day model. Livest Prod Sci, 44:37-44 (doi.org/10.1016/0301-6226(95)00051-L).

4. Daraban SV (2006). Technology sheep breeding. Ed. Risoprint, Cluj-Napoca, Romania, ISBN 973-751-182-4, 978-973-751-182-9.

5. Fogarty NM, Safari E, Taylor PJ, Murray W (2003). Genetic parameters for meat quality and carcass traits and their correlation with wool traits in Australian Merino sheep. Aust. J. Agric. Res., 54:715-722.

6. Ghiță E, Călătoiu A, Mariana R, Adriana V (2006). Preliminary investigations on the use of ICAR standardized methods to check the milk yield in sheep. Archiva Zootechnica, 9:135-146.

7. Kettunen A, Mäntysaari EA, Strandén I (1997). Analysis of First Lactation Test Day Milk Yields by Random Regression Model (http://agtr.ilri.cgiar.org/documents/Library/ docs/Interbull/bulletin16_files/docs/Kettunen.pdf).

8. Komprej A, Gorjanc G, Malovrh Š, Kompan D, Kovač $M$ (2003). Test day model and genetic parameters in Slovenian dairy sheep. In: Proceedings of the $54^{\text {th }}$ Annual Meeting of the EAAP, Rome, Italy, p. 351.

9. Mocnacs M, Taftă V, Vintilă I (1978). Genetics and breeding sheep. Ed. Ceres, Bucharest, Romania.

10. Oravcová $M$, Margetín $M$, Peškovičová $D$, Daňo J, Milerski M, Hetényi L, Polák P (2005). Factors affecting milk yield and ewe's lactation curves estimated with test-day models. Czech J Anim Sci, 51(11): 483-490.

11. Pascal C, Creangă Şt, Stan V, Gîlcă I (1997). Heritability estimation for different characteristics valued in youth sheep. Lucrări Științifice, vol. 39/40, Seria Zootehnie, USAMV Iaşi, ISSN 1454-7368, p. 153-158.

12. Pascal C, Cristian C, Nechifor I, Florea AlM (2014). Estimation of genetic parameters specific to Tुigaie breed reared in North-East part of Romania, Lucrări Ştiinţifice, vol. 62, Seria Zootehnie, USAMV Iași, ISSN 1454-7368, p. 3-8.

13. Pascal C, Gîlcă I, Ivancia M, Stăncescu L, Iftimie N (2009). Researches on the nursing capacity of Merinos of Palas sheep in growth from the North-Eastern part of Romania, Middle-European Buiatrics Congress, Folia Veterinaria, ISSN 0015-5748, p. 306-311.

14. Peralta-Lailson M, Trejo-González AÁ, Pedraza-Villagómez P, Berruecos-Villalobos JM, Vasquez CG (2005). Factors affecting milk yield and lactation curve fitting in the Creole sheep of Chiapas-Mexico. Small Rumin Res, 58:265-273. 
15. Ptak E,Schaeffer LR (1993). Use of test-day yields for genetic evaluation of dairy sires and cows. Livest Prod Sci, 34:23-34 (doi.org/10.1016/0301-6226(93)90033-E).

16. Safari E, Fogarty NM, Gilmour AR (2004). A review of genetic parameter estimates for wool, growth, meat and reproduction traits in sheep. Livestock Production Science, 92:271-289.

17. Taftă V, Vintilă I, Zamfirescu S (1996). Production, improvement and breeding sheep. Ed. Ceres București, Romania, ISBN 973-40-0408-5. 